
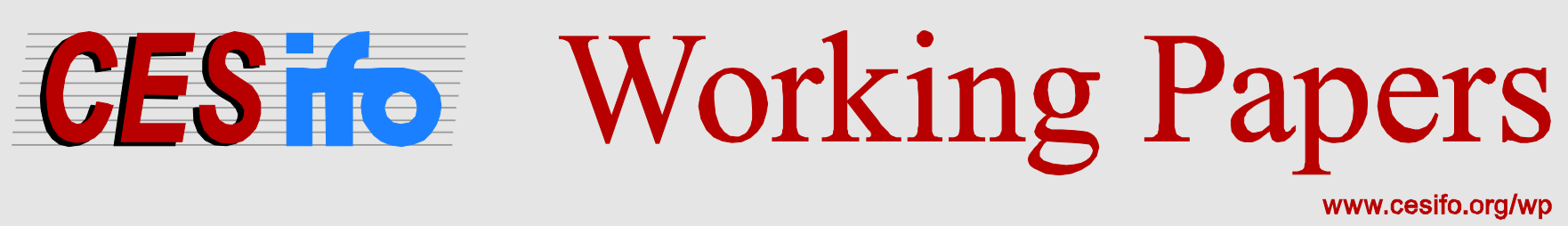

\title{
The Green Paradox: A Supply-side View of the Climate Problem
}

\author{
Hans-Werner Sinn
}

\author{
CESIFO WORKING PAPER NO. 5385 \\ CATEGORY 10: ENERGY AND ClimATE ECONOMICS \\ JUNE 2015
}

An electronic version of the paper may be downloaded

- from the SSRN website: Www.SSRN.com

- from the RePEc website: Www.RePEc.org

- from the CESifo website: www.CESifo-group.org/wp 


\title{
The Green Paradox: A Supply-side View of the Climate Problem
}

\begin{abstract}
Why have policies aimed at reducing the demand for carbon not succeeded in slowing down global carbon extraction and $\mathrm{CO}_{2}$ emissions, and why have carbon prices failed to increase over the last three decades? This comment argues that this is because of the Green Paradox, i.e. - (the anticipation of sales by resource owners who try to pre-empt the destruction of their markets by green policies.) - Reviewing some of the conditions under which strong and weak versions of the Green Paradox may emerge, it is argued that there is little hope that green replacement technologies will impose hard price constraints that would keep long-run extraction within a fixed carbon budget and that, therefore, even strong versions of the paradox cannot easily be avoided.
\end{abstract}

JEL-Code: O130, Q320, Q540, H230.

Keywords: carbon, environmentalism, back stop, oil prices.

Hans-Werner Sinn

Ifo Institute - Leibniz Institute for

Economic Research

at the University of Munich

Poschingerstrasse 5

Germany-81679 Munich

sinn@ifo.de 
The climate problem is one of mankind's biggest challenges. Averting disaster requires nothing less than worldwide collective policy action. However, policies that ignore the laws of economics may prove futile, if not downright counterproductive. In particular, policies aimed at reducing future demand for fossil fuels could backfire by inducing resource owners to bring forward their extraction plans, thus accelerating global warming. I have called this behaviour the Green Paradox.

Economists and policymakers alike long overlooked the possibility of a Green Paradox because the behaviour of resource owners played no specific role in the economics of climate change. Although it has long been recognized that the anthropogenic carbon accumulating in the atmosphere is basically the same as the carbon taken from the ground and that, except for sequestration, no technical devices exist that could change the proportions accumulating in the sea, biomass and atmosphere, this has rarely been incorporated into climate models or addressed by policymakers in the past. Instead the focus was on the demand side of the market. It was thought that to mitigate the climate problem, it would be effective and sufficient to require better insulation of homes, to extract higher mileage from car engines, to subsidize green energy through tariffs, to morally discredit fossil fuel consumption, to tax the use of fossil fuels, or to subsidize the development of green technologies, because it was taken for granted that supply would follow demand. Resource suppliers were perceived to be like car producers, facing flat marginal cost curves and producing what is demanded at given prices. However, unlike cars, fossil resources sold in the market are already there (i.e., in the earth's crust), and thus cannot be "produced" in the normal sense of the word. Extraction and exploration costs are typically small relative 
to user costs. This means that we cannot assume that the supply reactions of resource owners will be elastic.

Fortunately, the period of ignoring the obvious appears to be coming to an end. Although the supply-side view of the climate problem is not yet widely recognized by the public, both the IPCC and the literature on the economics of climate change are now giving at least as much weight to the supply side as to the demand side. The focus is on the intertemporal dimension of supply decisions, merging the traditional theory of exhaustible resources with the theory of climate change. Exhausting the stock of carbon resources in the ground and accumulating waste carbon in the atmosphere are now viewed and modelled as a single decision.

\section{The Hotelling View}

In the spirit of Hotelling (1931), the new models typically assume that resource owners optimize the composition of their wealth portfolios, with wealth consisting of both the physical resource in the ground and the financial wealth that can result from extracting and selling some of the resource. Ideally, resource owners will choose portfolios that equate the rates of return on both the physical and financial assets. However, resource owners are blind to the carbon externality they cause.

Under the Hotelling rule, it is essential that resource owners be forward-looking (i.e., that they base their behaviour on expectations of future prices). This means that policies aimed at limiting or reducing the possibility of generating resource-derived revenues in the future will induce resource owners to bring their sales forward to the present. This, in turn, will depress current market prices and increase resource demand, thus accelerating global warming. 


\section{The Green Paradox, Fossil Fuel Prices and Over-extraction}

In my view, the Green Paradox is not simply a theoretical possibility. I believe it explains why fossil fuel prices have failed to rise since the 1980s, despite decreasing stocks of fossil fuels and the vigorous growth of the world economy. The emergence of green policy movements around the world, rising public awareness of the climate problem, and increased calls for demand-reducing policy measures, ranging from taxes and demand constraints to subsidies on green technologies, have alarmed resource owners. In fact, while most of us perceived these developments as a breakthrough in the battle against global warming, resource owners viewed them as efforts that threatened to destroy their markets. Thus, in anticipation of the implementation of these policies, they accelerated their extraction of fossil fuels, bringing about decades of low energy prices. In fact, as of this writing (April 2015), oil prices, in real terms, are at about the same levels as just before the May 1979 price jump that led to the second oil crisis.

Concerns about the increasing influence of environmental activists may also explain the strange behaviour of the owners of German lignite fields. While Germany’s lignite resources rank tenth in the world and account for less than $2 \%$ of the available global stock, its $17 \%$ market share makes it the world's leader in terms of current extraction. What else but fear of threats from Germany's Green Party - arguably the world's most powerful environmental party - to close lignite mines and prohibit extraction can explain this behaviour?

Of course there are probably other reasons for over-extraction, including rising political tensions in the Middle East, which have increased the threat of expropriation. However, this only heightens the risk of global warming. For resource owners, it does 
not matter whether expropriation occurs through a coup d'état in a particular country, or through pressure from environmentalists to reduce dependence on fossil fuels. In either case, resource owners will seek to protect their interests by bringing at least some of their extraction forward.

This symposium on the Green Paradox and Climate Policy contains three important review articles written by experts in the field (Jensen, Mohlin, Pittel, and Sterner 2015; Long 2015; and van der Ploeg and Withagen 2015). The articles primarily present the theoretical literature because there has been very little empirical research on the Green Paradox to date. Using different models of fossil fuel extraction, they examine the impacts of a variety of announced or implemented green policies, focusing on the roles of stock-dependent extraction costs, spatially differentiated policies, and backstop technologies, in order to identify when well-intentioned policies are likely to backfire and result in a Green Paradox outcome. Overall, they find that the literature confirms the risk of Green Paradox outcomes and strengthens the case for taking a supply-side view of the climate problem.

While it is not possible to review the symposium articles in detail here, I would still like to comment on some of the key issues they raise.

\section{The Price Wedge}

My work on the Green Paradox (Sinn 2008a, 2008b, 2008c) focuses on the "price wedge" that may be created by green policies. Consider a baseline scenario (with an intertemporal market equilibrium and rational expectations) that is distorted by a green policy aimed at the demand side of the market (e.g., subsidies for green backstop technologies, enforced technological demand constraints, carbon taxes). This policy 
depresses producer prices during some periods relative to what they would have been without the policy, resulting in a price wedge. More specifically, I define the price wedge at a particular point in time as the difference between the old, pre-policy price and the new producer price, which would arise if suppliers did not adjust the fossil fuel extraction path to the new policy.

My analysis is based on the standard assumption made by traditional resource models whereby rising prices will always stay above (and be bounded away from) rising stock-dependent unit extraction costs due to increasing scarcity and on-going depletion. This assumption implies that laissez-faire markets will exhaust the available stock as time goes to infinity. Assuming marginal policy measures, I showed that producers will: 1. Bring their extraction forward if the present value of the expected price wedge (discounted using the rate of return on financial assets) increases over time;

2. Not change the extraction path if the present value of the expected price wedge remains constant over time; and

3. Postpone extraction if the present value of the expected price wedge decreases over time. $^{1}$

The first of the three outcomes is a Green Paradox, in both its weak and strong forms. It is a weak paradox because global warming accelerates at least for a while. It is a strong paradox because it moves the economy further away from an intertemporal

\footnotetext{
${ }^{1}$ This analysis draws on earlier work (Long and Sinn 1985) that examines the effects of exogenous price changes on extraction, as well as analysis of non-constant sales tax rates in a resource extraction model (Sinn 1982).
} 
Pareto optimum, which requires a slower speed of global warming than would occur in competitive markets. ${ }^{2}$

\section{Backstop Technologies}

Two of the symposium articles (van der Ploeg and Withagen and Jensen, Mohlin, Pittel and Sterner) emphasize the impact of a backstop technology that produces a perfect energy substitute at a fixed unit cost, thus preventing the extraction of fossil fuels with extraction costs above this unit cost. They also note that subsidies that reduce the unit cost of the backstop would accelerate global warming for a while (weak Green Paradox), but would reduce the total amount of carbon released into the atmosphere. For those who view reducing the carbon budget as the primary goal of climate policy, this is a satisfactory outcome.

Unfortunately, I am less optimistic about the potential role of backstop technologies. Firstly, it is not clear to me why reducing the total long-term carbon budget should be considered more beneficial to human welfare than postponing extraction. Focusing on the final carbon budget would make sense in a hypothetical world with no time preferences and discounting. But without discounting, a welfare analysis of resource extraction would be meaningless, even in the absence of global warming, as the optimal rate of resource extraction would be zero. I believe that even hard-core philosophers would agree that this problem excludes a lexicographic ordering of social preferences for postponing versus avoiding climate damages forever.

\footnotetext{
${ }^{2}$ See Sinn (2007, 2008a) for a generalization of the Solow-Stiglitz efficiency rule (Solow 1974; Stiglitz 1974) to the case of global warming due to the accumulation of carbon in the atmosphere.
} 
Secondly, I do not see anything in the real world that even comes close to being the perfect backstop assumed in theoretical models. Wind and solar power, often considered the most likely candidates, will be able to replace some fossil fuel, but certainly not all, because they are so volatile. The economic cost of storage devices such as pump storage or methanization plants that could smooth the supply of green electricity is extremely high. ${ }^{3}$ For example, in 2013, Germany would have needed 3,500 pump-storage plants, more than a hundred times the number it had at the time, to smooth its energy from wind and solar power, although the latter accounted for only $3 \%$ of final energy consumption. I fear that the only effective smoothing strategy would be one that is based on the intermittent production of energy from fossil fuel to cover periods when wind or solar is not available. But this smoothing strategy can only work if the green energy supply is small enough to prevent production spikes from exceeding aggregate demand, something that already occurs in Germany from time to time. Thus, beyond a certain production level, wind and solar energy would switch from being substitutes to complements of fossil fuels. This means that they cannot serve as the backstop technology assumed in many Green Paradox models.

Thus, at best, subsidies for green energy would reduce the demand for fossil fuels at all points in time, but would not impose the hard ceiling on prices assumed in the models. The subsidies would shift the (period-specific) resource demand curves downwards, creating the price wedge discussed earlier. At worst, subsidies for wind and solar energy would increase the demand for complementary fossil fuels if wind and

\footnotetext{
${ }^{3}$ See H.-W. Sinn, “Schafft es Deutschland, den Zappelstrom zu bändigen?”, public lecture, Ifo Annual Meeting, available at: http://mediathek.cesifogroup.de/iptv/player/macros/cesifo/mediathek?content=3583749\&idx=2\&category=2196209669.
} 
solar energy were already extensively used, thus reducing the price wedge at the margin.

Nuclear fission and nuclear fusion have the potential to serve as backstops that induce hard price ceilings. However, the former has been discredited by the Fukushima accident, and thus does not appear to offer a politically feasible alternative. Nuclear fusion could potentially garner more political support. However, decades of promises of imminent breakthroughs have given way to more pessimistic expectations. At best, the availability of a nuclear fusion backstop can be anticipated with time-dependent probabilities, but such probabilistic expectations translate into a mathematically expected price wedge that has implications similar to those discussed earlier.

\section{Scenarios that Avoid the Green Paradox}

Of course, there are model assumptions that would eliminate the risk of a Green Paradox outcome. For example, it is possible that mankind would, under laissez faire, not exhaust the entire resource stock, because, with the passage of time, the marginal willingness to pay for dwindling fossil resources rises more slowly than the unit extraction costs resulting from the depletion of the better fields. In this case, any permanent demand-reducing measures of the kind discussed earlier would eliminate some of the stock that could be profitably extracted, and hence put a limit on the earth's maximum temperature (see Withagen and van der Ploeg 2015). However, we cannot know today whether the underlying conditions for this optimistic scenario will hold because this all depends on technologies and preferences in a far distant and uncertain future. 
Alternatively, we might want to design a strategy that ensures a gradual decline in the present value of the price wedge over time, thus giving resource owners an incentive to extract later. However, I doubt that it will ever be politically possible to fine-tune such a policy and to commit to its implementation over the long term. In the real world, there are no commitment devices that bind successive generations. New generations of policymakers will re-optimize, and when the world does get warmer, they may face increasing political pressure to intensify their green policies, thus increasing the price wedge more than originally envisaged. In any case, resource owners are likely to anticipate such policy changes and react by bringing forward their fossil fuel extraction.

\section{Carbon Leakage}

The efficacy of demand policies may deteriorate further if only some resourceconsuming countries implement green policies, since their demand restraint would be outweighed by additional consumption in other countries. In this case, the Green Paradox would be reinforced by carbon leakage, rendering any unilateral actions toward solving the climate problem futile.

To illustrate this point, let's assume that the green policy consists of implementing a cap-and-trade system in a sub-group of countries, with quantity constraints tightening over time. Let's also assume for a moment that resource owners do not react by changing their extraction path. Under these conditions, at each point in time, the world market price for fossil fuels will be lower than it would have been without the policy because the cap reduces worldwide demand. Consumers in countries not participating in the emissions trading system would enjoy the lower world market 
price, and their energy demand would increase, while consumers in participating countries would be forced to pay a higher energy price and consume less because they would also have to pay for the emissions certificates. Consider now the possibility of an adjustment reaction affecting the extraction path and suppose that, without such an adjustment, the tightening of the cap would be fast enough to cause the present value of the world-market price wedge to increase over time. In this case, the price signal would again induce resource owners to bring forward extraction to the present to minimize revenue losses.

These green policies carried out by only a group of countries are inefficient for two reasons. Firstly, the energy no longer consumed by these countries will be consumed by non-participating countries instead. Secondly, the non-participating countries will also consume the additional quantities of energy that resource owners extract and sell because of the Green Paradox. In an initial phase, this would lead to more than $100 \%$ leakage because non-participating countries would consume more carbon than the countries introducing the cap-and-trade system would cut. ${ }^{4}$

\section{Conclusions}

My pessimistic conclusions about the efficacy of green demand-reducing policies have no doubt disappointed many environmental activists. However, the climate problem is too important to be left to ideologues. The purpose of green policies is not to provide the public with a warm glow from charitable actions, but rather to cool the earth.

\footnotetext{
${ }^{4}$ For a discussion of this possibility, see Sinn (2008b, c) and Long (2015).
} 
I would argue that nothing short of binding global agreements on quantity constraints can successfully reduce the speed of global warming. Measures that simply work through price signals are not sufficiently reliable to do the job, as it is the changes in prices, rather than their levels, that will determine success; and it is easy enough to get the price changes wrong through re-optimization by successive generations of policymakers.

The first step towards imposing quantity constraints should be to extend the existing UN emissions trading system (initially introduced through the Kyoto agreement) to the entire world, and to add national or supra-national cap-and-trade systems similar to Europe's. If the US, China and India could be convinced to sign such a treaty, $71 \%$ of worldwide $\mathrm{CO}_{2}$ output would be covered. In a second step, we should attempt to convince most of the rest of the world to participate. By definition, such a global system would be safe from international leakage and would not fall victim to the Green Paradox. In my opinion, this approach offers the only potential solution to the world's climate problem, which, as Stern et al. (2006) have remarked, is the world's greatest market externality ever.

\section{References}

Hotelling, H. (1931), “The Economics of Exhaustible Resources”, Journal of Political Economy, 39(2), 137-175.

Jensen, S., K. Mohlin, K. Pittel and T. Sterner (2015), “An Introduction to the Green Paradox: Climate Policy and Carbon Leakage", forthcoming in Review of Environmental Economics and Policy. 
Long, N.V. und H.-W. Sinn (1985), "Surprise Price Shifts, Tax Changes and the Supply Behaviour of Resource Extracting Firms”, Australian Economic Papers 24, 278289.

Long, N. V. (2015), “The Green Paradox in Open Economies: Lessons from Static and Dynamic Models”, forthcoming in Review of Environmental Economics and Policy.

Sinn, H.-W. (1982), “Absatzsteuern, Ölförderung und das Allmendeproblem”, in: H. Siebert (Hrsg.), Reaktionen auf Energiepreisänderungen, Lang, Frankfurt und Bern, 83-103.

Sinn, H.-W. (2007), "Pareto Optimality in the Extraction of Fossil Fuels and the Greenhouse Effect: A Note”, NBER Working Paper Nr. 13453, September 2007.

Sinn, H.-W. (2008a), "Public Policies Against Global Warming: A Supply Side Approach”, International Tax and Public Finance, 15(4), 360-394.

Sinn, H.-W. (2008b), Das grüne Paradoxon. Plädoyer für eine illusionsfreie Umweltpolitik, Econ: Berlin; English translation: The Green Paradox: A Supply Side Approach to Global Warming, The MIT Press, Cambridge, Mass., 2012.

Sinn, H.-W. (2008c), "Das grüne Paradoxon: Warum man das Angebot bei der Klimapolitik nicht vergessen darf”, Perspektiven der Wirtschaftspolitik 9 (special issue), 2008, 109-142.

Sinn, H.-W. (2014), “Schafft es Deutschland, den Zappelstrom zu bändigen?”, public lecture, Ifo Annual Meeting, 2 June 2014, http://mediathek.cesifogroup.de/iptv/player/macros/cesifo/mediathek?content=3583749\&idx=2\&category= 2196209669. 
Solow, R. (1974), “Intergenerational Equity and Exhaustible Resources”, Review of Economic Studies 41, 29 - 45.

Stiglitz, J. E. (1974), “Growth with Exhaustible Natural Resources. Efficient and Optimal Growth Paths”, Review of Economic Studies 41, 123 - 137.

Stern, N., S. Peters, V. Bakhshi, A. Bowen, C. Cameron, S. Catovsky, D. Crane, S. Cruickshank, S. Dietz, N. Edmonson, S.-L. Garbett, L. Hamid, G. Hoffman, D. Ingram, B. Jones, N. Patmore, H. Radcliffe, R. Sathiyarajah, M. Stock, C. Taylor, T. Vernon, H.,Wanjie und D. Zenghelis (2006), Stern Review: The Economics of Climate Change, HM Treasury, London.

Van der Ploeg, F. and Withagen, C. (2015), “Global Warming and the Green Paradox: A Review of Adverse Effects of Climate Policies", forthcoming in Review of Environmental Economics and Policy. 